\title{
Estudos organizacionais e movimentos sociais: o que sabemos? Para onde vamos?
}

\author{
Organization studies and social movements: What do we know? Where are we \\ going?
}

\author{
Maria Ceci Araujo Misoczky? \\ Rafael Kruter Flores ${ }^{2}$ \\ Sueli Maria Goulart Silva
}

\section{Resumo}

A teoria de movimentos sociais (MSs) - especialmente, a desenvolvida no contexto norte-americano - é fortemente influenciada pelos estudos organizacionais. No periodo recente, estudiosos de organizações também do contexto norteamericano têm, explicitamente, dialogado e compartilhado referenciais com a teoria de MSs, em busca de inspiração para tratar de fenômenos empresariais contemporâneos. Neste artigo, fazemos uma revisão dessa trajetória de aproximações, com foco na teoria da mobilização de recursos, na teoria da estrutura de oportunidades políticas e no esforço de convergência entre as mesmas, na aproximação recente entre teoria de movimentos sociais e teoria institucional e na abordagem de redes. Em vez de nos orientarmos pela pergunta sobre quais aprendizagens a gestão empresarial ter a partir da flexibilidade e fluidez dos MSs, perguntamos sobre as conseqüências que uma teoria fortemente influenciada pela lógica empresarial pode ter para nossa compreensão de movimentos que se orientam para a superação dessa lógica e das relações sociais por ela constituidas. Finalizamos apresentando uma agenda provisória sobre questões e opções que se encontram em nosso caminho.

Palavras-chave: teorias organizacionais; movimentos sociais; teoria da mobilização de recursos; teoria da estrutura de oportunidades politicas; teoria institucional.

\begin{abstract}
Social Movements' theory, mainly the one developed in the North-American context, is strongly influenced by organization studies. Recently, academics of the organizational field, also from the North-American context, have explicitly shared theoretical references with Social Movement's theories. In this article we review such trajectory of approximation, focusing on Mobilization Resources Theory, Structure of Political Opportunities and in the effort of connecting both, the recently approximation between Social Movements'theory and institutional theory, and network approach. Instead of orienting our question to the learning which enterprise's management can have with the flexibility and fluidity of Social Movements, we ask what would be the consequences of a theory strongly influenced by business logics to the understanding of movements oriented towards the overcome of such logic and the relations it produces. Finally, we present a provisory agenda of questions and options for further developments.
\end{abstract}

Key words: organizational theories; social movements; resources mobilization theory; structure of political opportunities theory; institutional theory.

\footnotetext{
${ }^{1}$ Doutora em Administração pela Universidade Federal do Rio Grande do Sul . Docente da Escola de Administração da Universidade Federal do Rio Grande do Sul - PPGA/UFRGS. Endereço: Escola de Administração/UFRGS - Av. Washington Luis 855 - Porto alegre/Rio Grande do Sul - Brasil - CEP: $90010-460$ - E-mail: mcamisoczky@ea.ufrgs.br

${ }^{2}$ Mestre em Administração/Organizações. Pesquisador no Programa de Pós-Graduação em Administração- Universidade Federal do Rio Grande do Sul - UFRGS. Endereço: Fernandes Vieira, 533/203 - Bom Fim - - Porto Alegre/Rio Grande do Sul - Brasil - CEP: 90035091. Email: rkflores@ea.ufrgs.br

${ }^{3}$ Doutora em Administração pela Universidade Federal de Pernambuco. Docente da Escola de Administração da Universidade Federal do Rio Grande do Sul PPGA/UFRGS. Endereço: Escola de Administração/UFRGS - Av. Washington Luis 855 - Porto alegre/Rio Grande do Sul - Brasil - CEP: $90010-460$ - E-mail: smgsilva@ea.ufrgs.br

Artigo submetido em Janeiro de 2008 e aceito em março 2008
} 


\section{Introdução}

A temática que abordamos neste artigo se fundamenta em necessidades surgidas a partir de nosso próprio trabalho de pesquisa. Na condição de estudiosos de organizações, temos nos defrontado com as insuficiências presentes em nosso campo disciplinar para abordar o tema dos movimentos sociais. Freqüentemente nos chamam à atenção de que tal objeto seria estranho à nossa disciplina. ${ }^{1}$ Como pano de fundo para essa afirmação, encontra-se claramente uma definição estreita de organização, entendida a partir do viés da formalidade estrutural. Em busca de argumentos para confrontar tais restrições, fomos à literatura sobre o tema e nos deparamos com uma intensa troca entre essas duas áreas teóricas - teoria dos movimentos sociais e teorias organizacionais. Inclusive, tivemos dificuldade de traçar uma linha divisória nítida entre ambas, como ficará evidente mais adiante.

Além disso, como afirma Fernandes (2001, p.50), "os movimentos sociais podem ser categorias de diferentes áreas de conhecimento, desde que os cientistas construam os respectivos referenciais teóricos". Considerando que os movimentos sociais desenvolvem processos, organizam, deliberam e produzem territórios das mais diversas formas - e, até mesmo, constroem estruturas -, não há como negar que se constituem em práticas de organização social. Portanto, se tomarmos como definidor do nosso campo disciplinar tanto o verbo quanto o substantivo, tanto o organizar como a organização, não há como negar o desafio e a propriedade, para nós, de estudar movimentos sociais considerando tanto nossa tradição teórica quanto suas insuficiências. Nesse sentido, a contribuição dos estudos organizacionais para a abordagem desses fenômenos envolve gerar construções teóricas marcadas pelas especificidades de nossa área temática sem, no entanto, abandonar as conexões dialógicas com o conhecimento gerado em outros campos disciplinares.

Com efeito, a revisão da literatura nos mostrou que a teoria dos movimentos sociais - especialmente, a desenvolvida no contexto norte-americano - é fortemente influenciada pelos estudos organizacionais. Além disso, em período recente, estudiosos de organizações têm, explicitamente, dialogado e compartilhado referenciais com as teorias sobre movimentos sociais (MSs), em busca de inspiração para enfrentar fenômenos empresariais contemporâneos.

Desse ponto-de-vista, é como se um círculo se fechasse, como se na metáfora do filho pródigo houvesse o retorno para casa. Entretanto, o que parece incomodar ou provocar questionamentos quanto ao nosso objeto de pesquisa - os movimentos sociais - é que, em vez de nos orientarmos pela pergunta sobre quais aprendizagens a gestão empresarial pode ter com a flexibilidade e fluidez dos MSs, pergumtamos sobre as consequiências que uma teoria fortemente influenciada pela lógica empresarial pode ter para nossa compreensão de movimentos que se orientam para a superação dessa lógica e das relações sociais por ela constituídas.

A preocupação subjacente às nossas perguntas é quanto às consequiências que tal suporte teórico - construído na fronteira entre movimentos sociais e teoria organizacional, além de fortemente influenciado pela versão dominante dos estudos organizacionais - teria para entender o momento atual dos movimentos sociais no Brasil e na América Latina.

Apresentamos, então, uma revisão da trajetória de aproximação entre as teorias, com destaque para a influência do pensamento organizacional norte-americano, dominante nos estudos organizacionais. Focalizamos a teoria da mobilização de recursos e a da estrutura de oportunidades políticas, o esforço de convergência entre ambas, a aproximação recente entre as teorias de movimentos sociais e institucional, bem como a abordagem de redes; essas duas últimas marcadas pela defesa da apropriação da teoria de MSs para estudar organizações do mundo dos negócios no contexto globalizado. Na seqüência, refletimos sobre as conseqüências de abordagens fortemente influenciadas pela lógica empresarial quando utilizadas como lentes para compreender movimentos orientados por outra lógica. Como parte dessas reflexões, apresentamos uma agenda provisória sobre questões e opções que se encontram em nosso caminho. 


\section{Movimentos sociais e organizações: o que sabemos?}

As teorias sobre MSs são usualmente classificadas em duas grandes vertentes: a européia e a norte-americana. $\mathrm{Na}$ européia, o foco é na identidade de um movimento social (MS) que se forma no interior da estrutura da dinâmica de conflitos de uma dada sociedade; ou seja, a análise não pode começar diretamente com atores, mas deve se iniciar com uma explicação sobre a emergência do ator. Essa vertente é conhecida como a teoria dos novos movimentos sociais. A vertente norte-americana - nomeadamente, a teoria da mobilização de recursos (TMR) e a teoria das oportunidades políticas (TEOP) e suas decorrências - trata os fundadores dos MSs como dados, focalizando as relações entre movimentos e instituições. Ao enfatizar a agência, a vertente norteamericana, diferentemente da européia, não considera as dinâmicas e a estrutura social que fazem emergir o movimento.

Abordamos, neste artigo, especificamente, a vertente norte-americana, considerando sua maior proximidade com os estudos organizacionais e sua expressiva influência sobre pesquisadores latino-americanos. Como ilustração inicial da proximidade entre a vertente teórica norte-americana sobre movimentos sociais e a versão dominante da teoria organizacional, citamos a constatação de Melucci (1989, p.194), para quem a origem e a ascensão de uma das teorias mais influentes - a da mobilização de recursos - deveu-se "ao desenvolvimento sem precedentes da teoria organizacional na análise de negócios e administração", nos EUA. O vínculo destacado pelo autor é, precisamente, o de uma suposição da racionalidade dos participantes em movimentos sociais, que se expressa através de metáforas sobre empreendedorismo.

No quadro 1, apresentamos uma síntese de aspectos e autores principais identificados nas teorias, nas vertentes norte-americana e européia.

\section{Quadro 1- Síntese das principais teorias sobre movimentos sociais}

\begin{tabular}{|c|c|c|}
\hline Teoria & Aspectos principais & $\begin{array}{l}\text { Autores } \\
\text { principais }\end{array}$ \\
\hline Escola de Chicago & $\begin{array}{l}\text { Entende os MSs como um comportamento coletivo de massas espontâneas } \\
\text { e amorfas, originados de alguma fonte de ansiedade ou frustração e que } \\
\text { levam à ruptura de padrões tradicionais da ordem e do controle social. Os } \\
\text { MSs produzem, então, formas elementares de comportamento coletivo que, } \\
\text { persistindo, podem evoluir para uma estrutura integrada e para o } \\
\text { estabelecimento de novas normas. }\end{array}$ & Herbert Blumer \\
\hline $\begin{array}{l}\text { Teoria do valor } \\
\text { agregado }\end{array}$ & $\begin{array}{l}\text { Propõe seis condições necessárias, não necessariamente seqüenciais, para o } \\
\text { desenvolvimento de um MS: } \\
\text { - condutividade estrutural: organizações da sociedade podem facilitar a } \\
\text { emergência de interesses conflitantes; } \\
\text { - filtros estruturais: a condutividade da estrutura social para conflitos } \\
\text { potenciais leva à percepção de que os interesses em conflito, de fato, } \\
\text { existem; } \\
\text { - crescimento e difusão de um sistema generalizado de crença: ideologia } \\
\text { como uma visão compartilhada da realidade que redefine a ação social e } \\
\text { serve como guia do comportamento; } \\
\text { - eventos precipitantes: dentro ou fora da estrutura social; } \\
\text { - atividades organizacionais: que transformam o potencial para a ação em } \\
\text { ação efetiva; } \\
\text { - operação de controle social: resposta de outros na sociedade, tais como } \\
\text { contra movimentos ou autoridades governamentais que alteram as } \\
\text { condições estruturais ou suprimem o movimento. }\end{array}$ & Neil Smelser \\
\hline $\begin{array}{l}\text { Teoria da } \\
\text { mobilização de } \\
\text { recursos }\end{array}$ & $\begin{array}{l}\text { Define MS como um conjunto de opiniões e crenças que representam } \\
\text { preferências para mudar alguns elementos da estrutural social ou da } \\
\text { distribuição de recompensas na sociedade. Enfatizam as condições que } \\
\text { facilitam a constituição de organizações de movimentos sociais (OMSs). }\end{array}$ & $\begin{array}{l}\text { John McCarthy; } \\
\text { Meyer; Zald }\end{array}$ \\
\hline
\end{tabular}


Teoria da estrutura das oportunidades políticas e Enfoque de dinâmicas de enfrentamento
Enfatizam a dinâmica que leva à insurgência, definindo MS como uma série de interações entre detentores de poder e pessoas que conseguem falar por aqueles que carecem de representação formal, tornando visíveis demandas por mudanças na distribuição ou no exercício do poder. Focalizam fatores Charles Tilly; estruturais, como a abertura ou o fechamento da arena política, a Sidney Tarrow; estabilidade de alianças políticas, a presença ou a ausência de elites aliadas e as divisões nas elites. $O$ fator estrutural é a variável explicativa em relação a duas variáveis dependentes: momento e resultado da atividade do movimento.

Tenta relacionar MSs com estruturas no nível macrossocial e com mudanças culturais. Para Touraine, os MSs são o comportamento coletivo organizado de um ator social lutando contra sua classe adversária pelo

Teoria dos novos movimentos sociais (vertente européia) controle da historicidade em uma comunidade concreta. Para Melucci, os MSs são uma classe específica de fenômeno coletivo: uma forma de ação coletiva que envolve a solidariedade, um conflito e o rompimento com os limites que o sistema pode tolerar sem alterar sua estrutura. Enfatiza a identidade dos atores e a cultura, as crenças generalizadas e os valores, além de focalizar as características da sociedade pós-industrial.

Os MSs se parecem com cadeias de eventos mais ou menos conectados, espalhados no tempo e espaço. Consistem em grupos de organizações, com

Teoria das redes de movimentos sociais vários níveis de formalização, ligados por padrões de interação mais ou menos centralizados, mais cooperativos ou mais hostis. Como atores ligados uns aos outros através de teias de troca, diretas ou mediadas, os MSs são estruturas altamente complexas e heterogêneas de redes.

Fonte: Dani (1992, 2003); Melucci (1989); McCarthy e Zald (1977); McAdam. McCarthy e Zald (1996); Tilly (1978); Touraine (1985) e Smelser (1962);

Segundo McAdam e Scott (2005), em meados da década de 1960, um grupo de jovens pesquisadores começou a formular argumentos políticos e organizacionais para tratar da insurgência social, transferindo seu foco do comportamento coletivo para a ação coletiva. Esses trabalhos questionavam as perspectivas que reduziam o fenômeno coletivo à convergência de comportamentos individuais, com um enfoque a partir da psicologia e entendendo os movimentos como meras respostas reativas a crises sociais - como se encontra, por exemplo, nos estudos de Smelser (1962). Com seu desenvolvimento, esses estudos vieram a compor a teoria da mobilização de recursos (TMR) e, de acordo com Diani (2000), nasceram a partir dos estudos organizacionais, em diálogo com a abordagem da escolha racional de Olson (1999). Nessa concepção de ação coletiva, os indivíduos se agregam para solucionar problemas que não poderiam ser enfrentados de outro modo; ou seja, uma afetação sentida no nível individual é canalizada, com elevados custos, para o nível coletivo, entendido como a maximização das ações individuais. Olson (1999) compara a ação de uma empresa ou da administração pública com a de um grupo social com interesses comuns. Coerções são necessárias para que os indivíduos arquem com os custos pessoais da ação coletiva.

Ao comentar a aproximação entre estudos organizacionais e uma teoria da ação coletiva que se propunha a ser uma teoria da dinâmica de grupos e de organizações, Diani (2000, p.5) conclui que:

Estamos aqui diante de um caso interessante de como uma perspectiva analítica desenvolvida e criativamente aplicada a um novo espaço empírico, para iluminar alguns processos específicos, se torna crescentemente popular entre praticantes cuja principal identificação intelectual é com o campo empírico específico, em vez de com a abordagem; e, eventualmente, essa perspectiva se transforma na teoria de outro objeto empírico.

A TMR, a partir de Olson (1999), pressupõe que a ação coletiva só é viável na presença de incentivos adequados e focaliza o papel dos fatores organizacionais. McCarthy e Zald (1977, p.1217), expoentes dessa abordagem, definem MSs como "um conjunto de opiniões e crenças em uma população, que representa preferências pela mudança de alguns elementos da estrutura social e/ou da estrutura de distribuição de 
recompensas de uma sociedade". Uma organização de movimentos sociais (OMS), por sua vez, é uma "organização complexa, ou formal, que identifica suas metas com as preferências de um MS, ou de um contramovimento, e tenta implementar essas metas" (McCARTHY; ZALD, 1977, p.1218). Ainda segundo esses autores, todos os MSs que têm em comum metas e preferências mais amplas constituem uma indústria de movimentos sociais - o análogo organizacional de um MS. Finalmente, um setor de movimentos sociais é composto de todas as indústrias de MSs em uma sociedade.

Na leitura de McAdam e Scott (2005, p.6) o trabalho desenvolvido no grupo de acadêmicos liderado por Zald privilegiou estrutura e processos organizacionais. Com base em desenvolvimentos anteriores dos estudos organizacionais, esses teóricos enfatizaram que os movimentos, "para se sustentar ao longo do tempo, requerem alguma forma de organização: liderança, estrutura administrativa, incentivos para participação e meios para adquirir recursos e apoio". Adotando uma concepção de sistema aberto, enfatizam as relações com o ambiente social, econômico e político. Além disso, seguindo as formulações de autores da sociologia funcionalista norteamericana, destacam a relação complexa e contraditória entre processos de organização e burocratização, de um lado, e a preservação dos compromissos ideológicos, de outro.

O modelo da mobilização de recursos enfatiza a interação entre a disponibilidade de recursos, as estruturas preexistentes de organização de preferências e as tentativas de empreendedorismo para satisfazer as demandas (McCARTHY; ZALD, 1977, p.1236). A posição dos autores é a de que os movimentos sociais são exercícios de cálculo voltados para a "fabricação do descontentamento". Para terem sucesso, esses incitamentos estratégicos têm que recorrer ao poder que lhes é conferido pela organização - vista como uma máquina maximizadora, na leitura de Alexander (1998). Essa concepção é a mesma que se encontra na definição de organização formal. Segundo Blau (1974, p.29), o "critério definidor da organização formal - ou uma organização, para simplificar - é a existência de procedimentos para mobilizar e coordenar os esforços" de vários subgrupos na busca de seus objetivos. No entanto, "as organizações só se concretizam como fonte de poder se houver disponibilidade de recursos, e essas condições externas de ação, que escapam ao controle subjetivo, são exatamente as que determinam a força da organização e, em decorrência, seu sucesso" (McCARTHY; ZALD, 1977, p.1221).

Percebe-se a vinculação à abordagem da interdependência com o ambiente, desenvolvida por Pfeffer e Salancik (1978), para quem as organizações necessitam de vários tipos de recursos: financeiros, materiais, humanos e informacionais. Para obtê-los, elas precisam interagir com aqueles que os detém. Scott (1981) sistematiza os aspectos relativos à mobilização de recursos, insistindo que as organizações não emergem espontaneamente; para que se constituam como tal, elas precisam identificar e conseguir acesso aos recursos. Entre os fatores que afetam o processo de mobilização, esse autor destaca: as condições quando da fundação da organização; o tipo de incentivo empregado para induzir as contribuições que afetam sua estrutura, assim como as características dos membros recrutados; e o ambiente em que a organização confronta a competição com outras pelos recursos disponíveis e que vai ajudar a moldar sua estrutura e estratégia distintiva.

Esse último fator está diretamente relacionado com três hipóteses centrais, desenvolvidas por McCarthy e Zald (1977): (a) a de que quando aumenta a quantidade de recursos disponíveis das massas e elites públicas, aumenta a quantidade tanto absoluta quanto relativa de recursos disponíveis para o setor de MSs; (b) a de quanto maior a quantidade absoluta de recursos disponíveis para o setor de MSs, maior a possibilidade de que novas indústrias de MSs e organizações de MSs se desenvolvam para disputar esses recursos; e (c) a de que quanto mais competitiva a indústria de MSs (em função do número e do crescimento das organizações de MSs existentes), maior a possibilidade de que novas organizações se proponham metas e estratégias mais limitadas.

Ainda com relação a esse tema, Aldrich (1979) estabelece uma ligação entre a taxa de nascimento de novas organizações e a taxa de fracassos, relacionando esse fenômeno com a correspondente dificuldade de adquirir recursos suficientes para a sobrevivência. Em outra direção, mas ainda sobre o tema da aquisição de recursos, Meyer e Rowan (1979, p.345) enfatizam a facilidade com que alguns tipos de recursos podem ser mobilizados para constituir uma organização. Referindo-se a sociedades desenvolvidas, os autores afirmam que "é preciso somente um pouco de energia empreendedora" para criar e sustentar uma organização em um ambiente 
institucionalizado - que contém regras, procedimentos aceitos, agentes autorizados e referências tomadas como dadas.

Permanecendo nessa direção podemos adotar a teoria da estrutura de oportunidades políticas (TEOP), considerada por McAdam, McCarthy e Zald (1996) como uma abordagem complementar à TMR. Desenvolvida por Tilly e pesquisadores associados, nela o foco se transfere para o ambiente político como estrutura geradora de oportunidades e limitações; ou seja, em muitas situações as condições para a ação coletiva são encontradas em arranjos sociais preexistentes - políticas institucionalizadas - que oferecem o capital social crítico para o sucesso de processos de mobilização emergentes (TILLY, 1978).

Essa teoria compartilha as concepções da TMR, inclusive, sobre a importância da organização interna, mas dirige sua atenção para as condições externas do ambiente no qual se desenvolve a ação coletiva. Aqui se pode fazer uma associação com a abordagem de Selznick (1959) e o caráter político atribuído por ele às organizações. Para ele, a burocracia é um mero instrumento racional que não dá conta das irracionalidades presentes nas relações, tanto internas quanto com o ambiente. Especificamente com relação a esse último, o autor destaca que os valores e eventos do ambiente podem condicionar a ação da organização.

A idéia central da TEOP é a de que os indivíduos sempre têm motivos para protestar e que estão dispostos a fazê-lo, desde que o custo seja razoável. Assim, segundo Tarrow (1994), os MSs emergem e se difundem como uma resposta às oportunidades políticas e, na sequiência, criam novas oportunidades através da ação coletiva.

Nessa abordagem, movimento social é definido como

um desafio, sustentado, aos detentores do poder, em nome de uma população que vive sob a jurisdição desses detentores do poder e por meio de repetidas demonstrações públicas da preocupação, unidade, número e compromisso dessa população. (TILLY, 1999, p.257)

Aqui, entram em cena as instituições do Estado, já que a estrutura de oportunidades depende, principalmente, de fatores como o caráter repressivo (ou permissivo) do regime político, a estrutura dos partidos políticos e o grau de representação de grupos de interesse nas instituições públicas.

Em produções mais recentes, os autores dessa corrente continuam a prestar atenção na relação entre atores e instituições, em um enfoque que considera o fluxo dos enfrentamentos. O enfoque da dinâmica de enfrentamentos (contentius dynamics) busca aspectos comuns - mecanismos e processos causais - em diferentes formas de luta que desafiam os limites entre políticas institucionais e não institucionais. Nesse sentido, categorizam as políticas de enfrentamento em inclusiva e transgressora. Na primeira, as partes em conflito são atores sociais previamente constituídos; na segunda (pelo menos, uma parte) emprega uma ação coletiva inovadora. Os processos podem ser contínuos ou episódicos. Esses últimos

criam incertezas e a possibilidade de conformação de novas identidades; revelam as linhas de fragmentação e tornam possíveis realinhamentos políticos; desafiam e entusiasmam os atores para continuar as lutas; forçam as elites a reconsiderar seus compromissos e alianças e deixam um resíduo de mudanças nos repertórios de lutas, práticas institucionais e alianças políticas. (McADAM; TARROW; TILLY, 2001, p.9)

No entanto, apesar dessa ampliação do foco, a lógica constitutiva dessa teoria continua a mesma, com um grande peso sendo conferido a fatores do ambiente.

Em um esforço para conectar e expandir o potencial explicativo da TMR e da TEOP, McAdam, McCarthy e Zald (1996, p.2) aproximam-nas da abordagem de mecanismos cognitivos através do framing process, que enfatiza a importância de idéias socialmente construídas e compartilhadas. Campbell (2005) identifica um giro cultural similar nos estudos organizacionais - notadamente, na abordagem neo-institucionalista -, quanto ao reconhecimento de que as estruturas e estratégias organizacionais são geradas por uma lógica de apropriação onde mudanças só podem ser propostas - ou mesmo reconhecidas como viáveis em um primeiro momento - se forem considerados os costumes, hábitos, esquemas e rotinas locais (DiMAGGIO; POWELL, 1983). 
Framing é, então, definido como "esforços estratégicos conscientes de um grupo de pessoas para modelar entendimentos compartilhados, do mundo e de si mesmos, que legitimam e motivam a ação coletiva".

Teóricos da mobilização de recursos focam o papel crítico dos recursos e da organização formal no surgimento de movimentos. O modelo do processo político destaca a importância crucial da expansão de oportunidades políticas como deflagradora da ação coletiva. Compartilhamos com os proponentes dessa perspectiva a convicção de que muitos movimentos políticos e revoluções são desencadeados por mudanças sociais que tornam a ordem política estabelecida mais vulnerável ou receptiva a desafios. Mas essas "oportunidades políticas" são apenas pré-requisitos necessários para a ação. $\mathrm{Na}$ ausência de organização suficiente - seja formal ou informal - tais oportunidades, possivelmente, não serão aproveitadas. [Além disso] ela só se tornará uma oportunidade quando for definida como tal por um grupo de atores suficientemente bem organizados para agir a partir dessa definição compartilhada da situação. [...] O framing process claramente encoraja a mobilização, na medida em que as pessoas procuram se organizar e agir a partir da crescente atenção com a ilegitimidade e a vulnerabilidade do sistema. Ao mesmo tempo, o potencial para o tipo de framing process crítico do sistema que descrevemos é, acreditamos, condicionado pelo acesso da população às várias estruturas de mobilização. (McADAM; MCCARTHY; ZALD, 1996, p.7-8)

Esses mesmos autores, na tentativa de infundir em suas construções teóricas "um sentido de dinamismo", recorrem à abordagem do ciclo de vida das organizações, tal como se encontra em Freeman (1982), propondo que a partir dessa aproximação seja possível analisar a emergência, o desenvolvimento e o declínio da ação coletiva.

Escrevendo sobre o tema da convergência entre movimentos e organizações, Davis e Zald (2005) defendem que os mecanismos subjacentes à ação coletiva são os mesmos para organizações e movimentos. Nessa formulação se encontra claramente expresso o viés da organização definida como coisa - como objeto formalizado e visível, através da sua conformação estrutural, que ao se vincular a um movimento social, ganha uma característica nova.

Movimentos sociais são frequentemente representados pela organização formal, enquanto organizações respondem a movimentos sociais e tem um movimento do tipo processo dentro deles. Assim, acadêmicos de ambas as áreas de estudo estão achando útil construir pontes ou fazer empréstimos através das fronteiras. $O$ ímpeto para maior intercâmbio vem de eventos do mundo e também de preocupações acadêmicas. À medida que as corporações se tornam crescentemente multinacionais e abrangentes, elas assumem um caráter político [...]. Processos análogos caracterizam a expansão de táticas de movimentos entre nações, seja através de redes de trabalho, de consumo ou de defesa dos direitos humanos, tentando moldar as agendas das corporações e Estados enquanto as regras da nova economia global se desenvolvem. Em uma economia globalizada, as novas formas de produção, a difusão da informação e de tecnologias de comunicação, bem como a mudança dos pólos de poder dos Estados para as corporações, geram pressões para a convergência nos processos de movimentos e organizações. (DAVIS; ZALD, 2005, p.336)

Essa convergência se torna possível graças à mudança de foco nos estudos organizacionais. Segundo Davis et al. (2005, p.2), os estudos organizacionais focavam unidades formais dirigidas por uma autoridade institucionalizada e os estudos de MSs, desafios para desestabilizar organizações e/ou instituições.

No caso dos estudos organizacionais, as análises se voltaram para a lógica institucional e para campos institucionais, nos quais as organizações estão linseridas. No caso dos MSs, o foco dominante tem sido no papel do ambiente político mais amplo, moldando a emergência e o desenvolvimento de movimentos.

Dadas essas aproximações, a categoria teórica que propiciaria a convergência seria a de campo organizacional. Essa categoria de campo organizacional, proposta por DiMaggio e Powell (1983), tanto permitiria compreender relações em um espaço específico da vida institucional como interações com o espaço social mais amplo; ou 
seja, as influências do ambiente institucional nas configurações de movimentos sociais, assim como nas organizações formais.

Tal aproximação estava anunciada desde a TMR; veja-se a formulação de McCarthy e Zald (1977) sobre os níveis de agregação: movimentos sociais, organizações de movimentos sociais, indústria de movimentos sociais e setor de movimentos sociais. Nessa crescente abrangência, a noção de campo permitiria ampliar as possíveis fontes de recursos, uma vez que tal noção remete à relevância da diversidade de atores que, independentemente de sua natureza, compartilham valores em um determinado espaço social.

Já na TEOP, a aproximação se anuncia pela necessidade de que as oportunidades políticas sejam percebidas como tais para que possam ser aproveitadas: o contexto de referência, categoria da vertente cognitiva da teoria institucional, daria conta de compreender processos dessa natureza. A percepção das oportunidades estaria, assim, vinculada ao esquema interpretativo dos indivíduos, orientando tanto sua percepção da realidade como suas ações. Em outras palavras, a ação seria conduzida a partir dos elementos do ambiente percebidos como relevantes para a sobrevivência e a legitimidade dos movimentos sociais.

Para que se efetive tal aproximação, McAdam e Scott (2005, p.17-19) propõem uma abordagem comum para o estudo de organização e o de movimentos, com base nas seguintes convenções analíticas:

1) campos organizacionais como unidade de análise fundamental;

2) definir a composição do campo em termos de três tipos de atores: os dominantes - aqueles indivíduos, grupos e organizações em torno dos quais as ações e interesses do campo tendem a se resolver; os desafiantes - aqueles indivíduos, grupos e organizações que procuram desafiar as posições vantajosas dos dominantes ou os aspectos procedimentais e estruturais fundamentais do campo; e as unidades de governança - aquelas unidades organizacionais que exercem poder e autoridade no nível do campo;

3) todos os campos existem dentro de ambientes mais amplos que contêm atores externos - aqueles indivíduos, grupos e organizações fora do campo focal, mas que, de algum modo, influenciam o curso da ação - e unidades externas de governança - estruturas de poder e autoridade operando no nível societal, provendo oportunidades e limites que afetam a ação no nível do campo;

4) atores sociais são constituídos por e têm seu comportamento guiado por diversas lógicas institucionais, incluindo valores, normas e crenças sobre relações meio-fim. As lógicas podem ser primárias - idéias que guiam e legitimam as ações dos atores dominantes - ou secundárias - idéias associadas aos atores emergentes ou oprimidos.

Embora afirmem estar convencidos da relevância desse conjunto básico de ferramentas para a análise de organizações e de movimentos sociais interessados em descrever períodos de conflito e mudanças num determinado campo, McAdam e Scott (2005) reconhecem que não são suficientes para explicar as origens de tais períodos. Assim, acrescentam três conceitos complementares:

1) muitos períodos de mudança-enfrentamento significante num campo começam com eventos desestabilizadores ou processos que, freqüentemente, têm sua origem fora dos limites estreitos do campo;

2) uma mobilização reativa é definida pelo seguinte conjunto de três mecanismos mobilizadores, altamente contingentes, que fazem a mediação entre as pressões para mudança e um período significativo de enfrentamentos no campo: atribuição de ameaça ou oportunidade, apropriação social, novos atores e ações inovadoras;

3) os resultados finais tendem a ser uma alteração significativa no alinhamento estratégico que previamente estruturava e estabilizava o campo, levando a novas acomodações institucionais. 
Clemens (2005) propõe uma agenda que integre o estudo empírico de MSs com estudos empíricos da organização formal, prestando atenção nas instituições políticas formais como o terreno para a integração e onde se poderiam analisar múltiplas formas e objetos de mobilização, restaurando a atenção na agência e na inovação estratégica por parte de ativistas e empreendedores. Mobilizados pelo foco na mudança institucional e reconhecendo a heterogeneidade nas formas de coordenação e no caráter das organizações, os estudiosos podem se inspirar nos múltiplos modelos de ação coletiva e nas diversas formas de relação que desenvolvem com outros atores organizacionais.

Essa aproximação entre disciplinas também se faz evidente na abordagem dos movimentos sociais como redes. Assim, movimentos sociais passam a ser definidos como "redes de interações informais entre uma pluralidade de indivíduos, grupos e/ou organizações, engajados em conflitos políticos ou culturais, com base em identidades coletivas compartilhadas" (DIANI, 1992, p.2). Alguns autores focam redes interpessoais como constitutivas de movimentos (PASSY, 2003), enquanto outros tratam de redes interorganizacionais e suas repercussões no que se refere à construção de alianças, à troca de informações, ao compartilhamento de recursos e ao pertencimento múltiplo de membros (DIANI, 2003).

Aqui se encontra a repercussão de desenvolvimentos teóricos produzidos nos estudos organizacionais, onde autores como Nohria e Eccles (1992) e Maintz (1993) refletem sobre a conformação e o significado de uma forma - organizações ligadas legal e economicamente através de estruturas de comando e controle - que não corresponde mais aos fenômenos observados. Passa a ser reconhecida, então, outra forma, definida como rede, quando organizações legalmente autônomas se articulam em função de sua forte interdependência, mas o fazem através de mecanismos de comando negociados e voluntários.

Podemos, finalmente, encerrar essa revisão apontando a perspectiva pela qual os movimentos sociais são uma fonte importante de inovação cultural e de criação de novas formas organizacionais que, por um lado, permitiriam o enriquecimento da teoria institucional, ao fundamentar para a noção de empreendedorismo institucional (RAO; MORRILL; ZALD, 2000) e, por outro, forneceriam evidências para o desenvolvimento teórico de construtos e mecanismos que melhor se ajustam à economia contemporânea (DAVIS; McADAM, 2000).

Em ambas as direções se pode identificar a tendência recente de aproximação entre os estudos sobre organizações e sobre movimentos sociais. Nada mais natural, se lembrarmos que a origem da vertente teórica norte-americana foi na disciplina dos estudos organizacionais, que ela retorna à casa paterna - em analogia com o retorno do filho pródico. Esse retorno, ao se realizar, explicita a sempre presente lógica orientadora de sua construção: a transposição para estudar movimentos sociais de suposições desenvolvidas a partir da análise racionalista e normativa orientada a fins. Portanto, é sem qualquer dificuldade que Zald (2005) pode escrever sobre a "ressurreição de uma idéia" ao rever um artigo do qual foi um dos autores - originalmente publicado em 1978 - e afirmar que ele continha idéias que hoje podem ser transpostas para promover mudança organizacional, inclusive, em ambientes corporativos. Também é sem dificuldades que Strang e Jung (1996) usam teoria de movimentos sociais para analisar a mudança organizacional no contexto do movimento da qualidade total (sic). Parece, também, natural buscar superar os limites da abordagem da governança corporativa e legal para explicar as políticas de controle corporativo recorrendo à abordagem de movimentos sociais (DAVIS; THOMPSON, 1994).

Exemplos com estes poderiam ser listados exaustivamente. No entanto, parecem suficientes para ilustrar e para justificar as congratulações de Clemens (2005, p.360): "Nesse ponto, os acadêmicos de movimentos sociais podem descansar e se congratular por terem desenvolvido um modelo de ação coletiva que agora é reconhecido pelos pesquisadores privilegiados das escolas de negócios”.

\section{Teorias organizacionais e movimentos sociais: para onde vamos?}

Cooper (1986, p.302) nos lembra que a linguagem acadêmica e as teorias que através dela se expressam são apenas um modo de falar a respeito, não um substituto do objeto ou fenômeno sobre o qual se fala. Por mais 
óbvio que isso pareça, às vezes nos esquecemos desse processo e tendemos a considerar a metalinguagem como o próprio real.

A metalinguagem, assim, se torna uma forma de representação que ignora ou esconde sua reapresentação ou seu papel de moldar, e atua como se fosse uma janela transparente que subrepticiamente - já que o pesquisador usualmente está desatento a isso-molda o que é percebido.

Em face dessa distração, o fato é que as teorias que produzimos (ou que reproduzimos) tanto permitem ver como impedem ver. Burrell (1997, p.18), na mesma direção, indica que "precisamos nos dar conta de que o que todo o conceito faz é excluir, assim como incluir".

Farinetti (2002, p.62), em busca de teorias para abordar a insurgência social no contexto latino-americano, indica que para avançar na compreensão das formas de conflitividade social, "é importante partir da base de que o problema não se aloja completamente no real, mas também em nossas lentes, nos conceitos que construímos para entender".

As abordagens revisadas, em decorrência de sua concepção sistêmico-funcionalista dos fenômenos, não conseguem superar a tirania da estrutura e, portanto, são incapazes de resolver a suposta contradição entre organização e movimento. Tilly (1988) afirma que movimentos sociais não são organizações, sequer um tipo peculiar de organização. Por mais singelo que pareça, a oposição que o autor faz é entre o fixo e o dinâmico, oposição essa que se pretenderia resolver com a adoção do conceito de rede. Della Porta e Diani (2006), defendendo essa posição, argumentam que a grande rigidez e a estrutura mais hierárquica que as organizações apresentam não se aplicam aos movimentos sociais. Sim, não se aplicam. No entanto, como estudiosos de organizações, sabemos que existem abordagens processuais, pelo menos, desde as formulações de Weick (1973, 1995), passando pelos trabalhos de Cooper $(1976,2005)$.

Um caminho possível seria, então, contribuirmos para a fertilização mútua entre estudos de organizações e de movimentos sociais, a partir de teorias que relacionam estrutura e processo, entrando nesse terreno ainda dominado por abordagens que não conseguem superar sua incapacidade de tratar a agência e a dinâmica social - como é o caso da teoria institucional. No entanto, para que isso ocorra, seria preciso incluir na nossa agenda de reflexões as dificuldades inerentes à nossa categoria central: a organização. Burrell (1997, p.25), inclusive, já havia chamado esse termo de "subteorizado". Aliás, junto com Cooper, esse autor vem há vários anos chamando a atenção para que dirijamos nosso olhar para a produção da organização e não para a organização da produção (COOPER; BURRELL, 1988). A possibilidade de trilhar esse caminho parte da suposição de que, pelo menos, no cenário internacional de nossa disciplina, não há qualquer dúvida quanto à pertinência do objeto de estudo movimentos sociais ao nosso campo disciplinar, como ficou evidenciado até aqui. Permanece, no entanto, uma interdição, que Clemens (2005, p.363) expressa literalmente. Ao enfatizar as potencialidades do encontro entre organizações e movimentos sociais - considerando a fertilização potencial dos estudos das primeiras pelas teorias de movimentos sociais -, a autora impõe uma condição: desde que os pesquisadores organizacionais "evitem replicar o foco na esquerda, que tende a caracterizar essa literatura".

Será, então, que a interdição encontrada em nosso contexto não se refere ao objeto de estudo em si, mas aos riscos, que lhes são associados, de contaminação da disciplina por posições ideológicas de contestação à lógica do capital? Isto é, tal interdição é consequiência do papel desempenhado por nossa disciplina na produção ativa de não-existências, ocorrida sempre que certa entidade ou fenômeno é declarado - pelo conhecimento acadêmico hegemônico - invisível, não inteligível ou irreversivelmente dispensável (SANTOS, 2006).

Burrell (1997, p.12), em uma reflexão sobre a teoria organizacional, afirma que o que ela tem feito é eliminar e suprimir tantas abordagens e aspectos da realidade, de tal modo que "muitos dos que habitam partes relevantes das nossas vidas têm mantido suas cabeças baixas de tal modo que, sequer, percebemos sua existência".

De fato, não parece haver problemas quando as fronteiras são atravessadas preservando-se a lógica do mundo dos negócios que, quando transposta para a abordagem dos movimentos sociais, produz a não-existência de práticas organizativas não estruturadas, não duradouras, sem lideranças empreendedoras e para as quais não se 
consegue identificar relações racionais de custo/benefício. A categoria "sucesso", acoplada a essa lógica, remete sempre ao atingimento de objetivos; declarando não-existentes os processos sociais que podem fracassar com relação aos objetivos explícitos, mas que produzem transformações culturais importantes na sociedade. Além disso, tal lógica não permite compreender a existência de lutas sociais que não são concessões da estrutura do sistema, tais como insurgências populares em contextos de repressão e sem organização prévia nas quais o custo de oportunidade é muito elevado. Tal fenômeno é, então, declarado irrelevante ao ser explicado pela irracionalidade das massas. Mesmo a abordagem de redes, do modo como é adotada, transforma-se em um modo de operacionalizar a estrutura social, tornando ininteligíveis práticas que não se orientam por negociações nem pela construção de alianças em um contexto estrutural de atores préconstituídos, sempre em decorrência da predominância da racionalidade instrumental.

Assim, a concepção de racionalidade subjacente a essas teorias, com foco no interesse egoístico e no cálculo para satisfazê-lo, torna não-existentes práticas organizativas orientadas por convicções valorativas sobre o mundo social. Aliás, a própria ação é um problema para o conjunto teórico aqui revisado. Ao priorizar o "como" em vez dos "motivos para a ação", restringe nossa compreensão dos MSs aos espaços institucionalizados e elitizados da ação política (CROSSLEY, 2002). Ao fazê-lo, declara não-existentes os movimentos que se organizam para a construção de espaços sociais orientados para a reprodução da vida em comunidade, como, por exemplo, nas organizações de desempregados que, espalhadas pela Grande Buenos Aires, constroem coletivos à margem da dependência das políticas públicas (SVAMPA; PEREYRA, 2005).

Fazemos essas considerações a partir do entendimento de que as disciplinas também são campos de poder e, portanto, espaços de disputa. Bourdieu (1996, p.118) chama de "subversão herética" o ato de explorar a possibilidade de mudar o mundo transformando a representação que dele se faz. Podemos, então, delinear outro caminho possível, marcado pela solidariedade e co-presença junto aos movimentos sociais. Um modo de fazêlo é refletir sobre e tornar visíveis aqueles processos de organização da resistência e de lutas sociais que tendem a ser ignorados pelo discurso organizacional contemporâneo - em decorrência das limitações acima apontadas. Para isso, defendemos a adoção de uma postura que Böhm (2002) denomina de prática teórica, referindo-se à intensa conexão entre teoria e prática, ainda que deixe espaço para a relativa autonomia de uma com relação à outra. Essa concepção se concretiza no engajamento dos pesquisadores nos movimentos populares, bem como em reflexões que questionem e concretamente afetem suas organizações, contribuindo para um projeto de mudança radical.

Trilhar esse caminho inclui a difícil prática de revisar nossas suposições de "saber fazer", de "saber a resposta", as quais não correspondem nem à experiência que se desenvolve em nosso tempo, nem às necessidades dos atores-sujeitos envolvidos nas lutas sociais. Trilhá-lo supõe articular duas dimensões do pensamento reflexivo crítico: o saber que é elaborado na dimensão estritamente teórica no âmbito estritamente teórico com o saber que vem de baixo e que fica, na sua maior parte, contido nas práticas. Daí a importância de resgatar, sistematizar e conceituar essas práticas. A articulação dessas dimensões possibilita a construção dialética do diálogo de saberes, indispensável para a produção de um novo pensamento estratégico. Esse estudo, baseado no diálogo horizontal de saberes, e numa construção articulada dos mesmos, resulta nas novas dimensões do desempenho daqueles que nos acostumamos a identificar como o intelectual orgânico: não como o que sabe e orienta, mas como o que constrói junto com os atores-sujeitos existentes numa sociedade concreta, e a partir de suas realidades (RAUBER, 2004).

\section{Considerações finais}

As matrizes teóricas que orientam os pesquisadores de movimentos sociais utilizam como categorias de análise a dependência de recursos e a capacidade para mobilizá-los num momento de oportunidade política, a estruturação (framing) e a institucionalização. Isto é, além de depender dos recursos, os MSs dependem também da oportunidade política outorgada pela configuração do campo onde estão inseridos. Essas abordagens reproduzem uma concepção empresarial dos MSs, pelo peso que conferem à liderança, à importância da organização formal e ao peso do ambiente para o sucesso de um empreendimento. Segundo essa 
lógica, os setores não privilegiados da sociedade seriam praticamente incapazes de iniciar movimentos insurgentes. Além disso, seria inviável a erupção de movimentos em contextos adversos e repressivos. Adotar essas lentes produz a não-existência das insurgências populares que se espalham por toda a América Latina nos últimos anos, bem como os movimentos de resistência aos regimes ditatoriais do passado.

Percebemos, também, que a teoria abstraída das organizações capitalistas do contexto norte-americano do século passado é utilizada para explicar os atuais movimentos sociais, muitas vezes anticapitalistas e em outros contextos. Mais recentemente, no contexto da globalização dos mercados e das corporações transnacionais, as práticas dos movimentos sociais passam a servir de referência para a proposição de modelos e instrumentos de gestão empresarial.

Como parte de uma agenda para reflexão, perguntamos sobre as consequiências da utilização de uma teoria orientada pela lógica empresarial para explicar a práxis de sujeitos orientados por uma lógica distinta. Quais as implicações de se estudar os movimentos sociais a partir das matrizes teóricas estabelecidas nos estudos organizacionais? Quais as consequiências disso para a práxis desses movimentos? Não estaríamos, ao fazê-lo, contribuindo para subverter a lógica orientadora dessa práxis?

O retorno à origem da literatura nos alertou para o fato de que a tentativa de unir a teoria organizacional dominante à dos movimentos sociais apenas contribui para a reprodução do sistema, contrariando a lógica desses movimentos. Seja aplicando a nossa teoria ao fenômeno dos MSs, seja abstraindo desse fenômeno novas teorias à luz do referencial organizacional dominante, estaremos sempre trabalhando para manter e reproduzir a ordem vigente.

Sem dúvida, não estamos interessados em desenvolver um modelo de ação coletiva para sermos reconhecidos nas escolas de negócios e, então, descansar e nos congratularmos, como sugeriu Clemens (2005). Estamos, sim, interessados em retornar aos movimentos sociais para dali abstrairmos possibilidades teóricas comprometidas com sua práxis, pois uma das certezas que temos é a de que os movimentos sociais se constituem em (e através de) práticas organizacionais que a nossa disciplina, em sua configuração atual, não permite compreender.

De modo coerente, também consideramos nosso fazer acadêmico uma luta social. Nesse sentido, em vez de abandonarmos nosso campo disciplinar, pensamos ser possível transformá-lo, explorando os processos de organização de resistências e lutas sociais que tendem a ser ignorados pelo discurso organizacional contemporâneo. Ao fazê-lo, estaremos contribuindo para contestar a hegemonia da organização como sinônimo de empresa - parte importante da hegemonia das relações capitalistas globais que se articula em todos os lugares em que estamos cotidianamente, e onde uma forma de organização e de ser da sociedade se naturaliza como fatalidade, decretando todas as outras como não existentes (MISOCZKY; FLORES; BÖHM, 2008). Finalmente, a pertinência teórica vem da relevância empírica do próprio objeto, uma vez que a realidade brasileira e latino-americana é marcada pela atuação política de movimentos sociais combativos que, à sua maneira, tomam parte nas questões que os afetam e, assim, constroem a sociedade e o Estado. 


\section{Referências}

ALDRICH, Howard E. Organizations and environment. Englewood Cliffs: Prentice-Hall, 1979.

ALEXANDER, Jeffrey C. Ação coletiva, cultura e sociedade civil: secularização, atualização, inversão, revisão e deslocamento do modelo clássico dos movimentos sociais. Revista Brasileira de Ciências Sociais, São Paulo, v.13, n.37, 1998. Disponível em: <http://www.scielo.br/scielo.php?script=sci_arttext\&tpid=S010269091998000200001\&tIng=en\&tnrm=iso>. Acesso em: 20 mar. 2007.

BLAU, P. M. On the nature of organizations. New York: Wiley, 1974.

BÖHM, Steffen. Movements of theory and practice. Ephemera, v.2, n.4, 2002.

BOURDIEU, Pierre. A economia das trocas lingüísticas. São Paulo: Edusp, 1996.

BURRELL, Gibson. Pandemonium: toward a retro-organization theory. London: Sage, 1997.

CAMPBELL, John L. Where do we stand? Common mechanisms in organizations and social movement research. In: DAVIS, Gerald F. et al (Ed.). Social movements and organization theory. Cambridge: Cambridge University Press, 2005. p.41-68.

CLEMENS, Elisabeth S. Two kinds of stuff: the current encounter of social movements and organizations. In: DAVIS, Gerald F. et al. (Ed.). Social movements and organization theory. Cambridge: Cambridge University Press, 2005. p.351-365.

COOPER, Robert. The open field. Human Relations, v.29, n.11, p.999-1017, 1976.

Organization/disorganization. Social Science Information, v.25, n.2, p.299-335, 1986.

Peripheral vision: relationality. Organization Studies, v.26, n.11, p.1689-1710, 2005.

; BURRELL, Gibson. Modernism, postmodernism and organizational analysis: an introduction. Organization Studies, v. 9, n.2, p.221-235, 1988.

CROSSLEY, Nick. Making sense of social movements. Buckingham: Open University Press, 2002.

DAVIS, Gerald F. et al. Preface. In: (Ed.). Social movements and organization theory. Cambridge: Cambridge University Press, 2005. p.xiii-xviii, p.1-13.

DAVIS, Gerald F.; McADAM, Doug. Corporations, classes, and social movements after managerialism. Research in Organizational Behaviour, v.22, p.195-238, 2000. 174,1994

THOMPSON, Tracy A. A social movement perspective on corporate control. Administrative Science Quarterly, v.39, n.1, p.141-

; ZALD, Mayer N. Social change, social theory, and the convergence of movements and organizations. In: DAVIS, Gerald F. et al. (Ed.). Social movements and organization theory. Cambridge: Cambridge University Press, 2005. p.335-350.

DELLA PORTA, Donatella; DIANI, Mario. Social movements: an introduction. Oxford: Blackwell, 2006.

DIANI, Mario. The concept of social movement. The Sociological Review, n.40, p.1-25, 1992.

. Networks and social movements: from metaphor to theory? In. CONFERENCE ON SOCIAL MOVEMENT ANALYSIS: THE NETWORK PERSPECTIVE, 23-25 June 2000, Loch Lomond.

Networks and social movements: a research programme In: DIANI, Mario; McADAM, Doug (Ed.). Social movements and networks: relational approaches to collective action. Oxford: Oxford University Press, 2003. p.299-319.

DiMAGGIO, Paul J.; POWELL, W. Walter. The iron cage revisited: institutional isomorphism and collective rationality in Organizational Fields. American Sociological Review, n.48, p.147-160, 1983.

FARINETTI, Marina. La conflictividad social después del movimiento obrero. Nueva Sociedad, n.182, p.60-75, 2002.

FERNANDES, Bernardo Mançano. Questão agrária, pesquisa e MST. São Paulo: Cortez Ed., 2001.

FREEMAN, J. Organizational life cycles and natural selection processes. In: STAW, B. M.; CUMMINGS, L. L. (Ed.). Research in organizational behavior. Greenwich: JAl, 1982.

MAINTZ, R. Modern and the logic of interorganizational networks. In: CHILD, John; CROZIER, Michel; MAINTZ, R. Societal change between market and organizations. Aldershot: Avebury, 1993. p.3-18.

McADAM, David.; TARROW, Sydney; TILLY, Charles. Dynamics of contention. Cambridge: Cambridge University Press, 2001.

McADAM, Doug. Conceptual origins, current problems, future directions. In: McADAM, Doug; McCARTHY, John D.; ZALD, Mayer N. (Ed.). Comparative perspectives on social movements: political opportunities, mobilizing structures, and cultural framings. Cambridge: Cambridge University Press, 1996. p.23-40. 
; MCCARTHY, John D.; ZALD, Mayer N. Introduction: opportunities, mobilizing structures, and framing process - toward a synthetic, comparative perspective on social movements. In: (Ed.). Comparative perspectives on social movements: political opportunities, mobilizing structures, and cultural framings. Cambridge: Cambridge University Press, 1996. p.1-22.

; SCOT, W. Richard. Organizations and movements. In: DAVIS, Gerald F. et al. (Ed.). Social movements and organization theory. Cambridge: Cambridge University Press, 2005. p.4-40.

McCARTHY, John D.; ZALD, Meyer. Resource mobilization and social movements: a partial theory. American Journal of Sociology, v.82, n.6, p.1212-1241, 1977

MELUCCI, Alberto. Nomads of the present: social movements and individual needs in contemporary society. Philadelphia: Temple University Press, 1989.

MEYER, John W.; ROWAN, Brian. Institutionalized organizations: formal structure as myth and ceremony. American Journal of Sociology, v.83, p.340-363, 1979.

MISOCZKY, Maria Ceci; FLORES, Rafael Kruter; BÖHM, Steffen. A práxis da resistência e das lutas sociais e a hegemonia da organização. 2008. No prelo.

NOHRIA, N.; ECCLES, R. Networks and organizations: structure, form and action. Boston: Harvard Business School Press, 1992.

OLSON, Mancur. A lógica da ação coletiva: os benefícios públicos e uma teoria dos grupos sociais. São Paulo: Edusp, 1999.

PASSY, Florence. Social networks matter. But how? In: DIANI, Mario; McADAM, Doug (Ed.) Social movements and networks: relational approaches to collective action. Oxford: Oxford University Press, 2003. p.21-48.

PFEFFER, Jeffrey; SALANCIK, Gerald R. The external control of organizations. New York: Harper \& Row, 1978.

RAO, Hayagreeva; MORRILL, Calvin; ZALD, Mayer. Power plays: how social movements and collective action create new organizational forms. Research in Organizational Behaviour, v.22, p.239-282, 2000.

RAUBER, Isabel. La transformación social en el siglo XXI: camino de reformas o de revolución. Pasado y Presente XXI, jun. 2004.

SANTOS, Boaventura de Sousa. A gramática do tempo: para uma nova cultura política. São Paulo: Cortez Ed., 2006.

SCOT, W. Richard. Organizations: rational, natural, and open systems. Englewood Cliffs: Prentice-Hall, 1981.

SELZNICK, Philip. TVA and the grass roots. New York: Harper \&t Row, 1959.

SMELSER, Neil. Theory of collective behavior. New York: Free Press, 1962.

STRANG, David; JUNG, Dong-II. Organizational change as an orchestrated social movement: recruitment to a corporate quality initiative. In: McADAM, Doug; McCARTHY, John D.; ZALD, Mayer N. (Ed.) Comparative perspectives on social movements: political opportunities, mobilizing structures, and cultural framings. Cambridge: Cambridge University Press, 1996. p.280-309.

SVAMPA, Maristella; PEREYRA, Sebastian. La política de los movimientos piqueteros. In: SCHUSTER, Federico L. et al. (Comp.). Tomar la palabra: estudios sobre protesta social y acción colectiva en la Argentina contemporánea. Buenos Aires: Prometeo Libros, 2005. p.343364.

TARROW, Sydney. El poder em movimiento: los movimientos sociales, la acción colectiva y la política. Madrid: Alianza Editorial, 1994.

TILLY, Charles. From mobilization to revolution. Reading: Addison-Wesley, 1978.

Social movements: old and new. In: KRIESBERG, L. (Ed.). Research in social movements, conflict and change. Greenwich, JAI Press, 1988. p.1-18.

From interactions to outcomes in social movements. In: GIUGNI, M.; McADAM, David.; TILLY, C. (Ed.). How movements matter. Minneapolis: University of Minneapolis Press, 1999. p.253-270.

TOURAINE, Alain. An introduction to the study of social movements. Social Research, n.52, p.749-788, 1985.

WEICK, Karl. A psicologia social da organização. São Paulo: Edgard Blucher, 1973.

Sense making in organizations. London: Sage, 1995.

ZALD, Mayer N. The strange career of an idea and its resurrection: social movements in organizations. Journal of Management Inquiry, v.14, n.2, p.157-166, 2005

${ }^{1}$ Esse gesto representa, claramente, uma interdição, o uso da disciplina como mecanismo de controle sobre o discurso, como Foucault nos ensina. Apesar de termos consciência desse fenômeno, ele não será tratado nesse artigo. A esse respeito, ver Misoczky, Flores e Böhm (2008). 